gestión de los alimentos, el metabolismo de medicamentos y el mantenimiento de la salud en general.

De hecho, en cada organismo humano hay 10 veces tantas células microbianas como humanas. Jeffrey Gordon, microbiólogo de la Universidad Washington en St. Louis, declara que nuestro componente microbiano está muy evolucionado y ha aprendido a adaptarse a la vida con nosotros. Hoy día, nuestras comunidades bacterianas son de sumo interés para los investigadores que se esfuerzan por conocer tanto la salud como las enfermedades, especialmente las que no se pueden diagnosticar claramente o tratarse con eficacia. Las nuevas técnicas de laboratorio nos han permitido conocer más de cerca a esos invisibles inquilinos y varios grupos de científicos ya han informado que cualquier interferencia disruptiva tiene consecuencias negativas para nuestra salud, p. ej., obesidad, enteropatía inflamatoria e infecciones vaginales y de las encías. En realidad, los científicos reconocieron su importancia hace tiempo.

Ya en el siglo XIX, Louis Pasteur sabía que perjudicar nuestras bacterias normales causaba enfermedad. Sin embargo, hasta hace poco era difícil estudiarlas, porque la mayoría no se pueden cultivar en el laboratorio. Ahora se puede extraer ADN de una muestra e identificar rápidamente miles de especies bacterianas sin cultivar ninguna. Los estudios más recientes indican que los microbios trabajan juntos en comunidad para influenciar la salud, hallazgo que seguramente tendrá un gran impacto sobre nuestro conocimiento de lo que es enfermedad. David Relman, investigador de enfermedades infecciosas de la Universidad de Stanford, dice que en vez de pensar en la enfermedad como la ausencia o presencia de un solo agente patógeno, debemos pensar en la colectividad.

Por su parte, Jeffrey Gordon, explica que el intestino está lleno de microbios que interactúan entre sí y con el huésped para beneficio de todos. Gordon y su grupo transplantaron comunidades microbianas intestinales de ratones normales a ratones criados en un ambiente estéril, los cuales pronto comenzaron a acumular grasa en sus tejidos. En ellos se había suprimido el factor que regula el almacenaje de energía. Seguidamente compararon la microbiota de ratones obesos y delgados y se sorprendieron de encontrar una gran diferencia entre los dos tipos de bacteria que normalmente habitan el intestino. Los que se crían para ser obesos tienen una mayor proporción de cierto tipo de bacterias y viceversa. $\mathrm{Al}$ transferir microbios de ratones obesos y delgados a ratones exentos de microbios, los primeros engordaron marcadamente. El grupo estudió por un año dos pequeños grupos de personas sometidas a dieta $\mathrm{y}$ en ellos aumentaron las bacterias "de enflaquecimiento" y disminuyeron las de gordura.
A raíz de esos interesantes descubrimientos, se han empezado muchos nuevos estudios. En las microbiotas de personas con enfermedad de Crohn se encontró un mayor número de Escherichia coli y Pseudomonas que en personas con colitis ulcerosa o sanas. También se ha descubierto que las comunidades microbianas afectan no solo al intestino sino a otras partes del organismo y se está investigando el síndrome de vaginosis bacteriana, infección que se encuentra en $10 \%$ a $20 \%$ de las mujeres de los Estados Unidos. En este caso se identificaron 35 especies asociadas con el síndrome, la mitad de ellas desconocidas hasta entonces. El microbiólogo David Fredricks opina que las causantes de la vaginosis son metabólicamente interdependientes y actúan en comunidad, sin poder existir independientemente.

En estudios de trastornos dermatológicos se siguen descubriendo cientos de nuevas bacterias que varían de una persona a otra y aun de una parte del mismo cuerpo a otra. Todas estas observaciones muestran la complejidad de crear agentes terapéuticos frente al número tan grande de miembros interactivos en las comunidades bacterianas. Sin embargo, los adelantos en la tecnología para secuenciar el ADN y en informática permiten abrigar la esperanza de que la tarea de conocer nuestras bacterias y entender su función en la salud y las enfermedades tenga algún día aplicaciones prácticas de beneficio para el ser humano. (Goho A. Our microbes, ourselves. Science News. 2007;171:314-316.)

\section{Frecuencia de los síntomas de menopausia $y$ riesgos asociados en Ecuador}

Mientras más temprano comienzan los síntomas de la menopausia, más tiempo está la mujer expuesta a los efectos negativos de la falta de estrógeno, responsable de cambios fisiológicos y psicológicos que afectan a su calidad de vida. La edad media de presentación de la menopausia en las mujeres ecuatorianas, como en otros países de América Latina, ocurre antes que en las mujeres estadounidenses y europeas, hecho que se ha asociado, entre otros factores, con la mayor altitud en que viven y su menor nivel educacional y socioeconómico.

En este trabajo se analiza la frecuencia de los síntomas de menopausia y los riesgos relacionados en una población de mujeres postmenopáusicas de Ecuador que participaron en un programa de tamizaje metabólico.

En este estudio transversal participaron 325 mujeres postmenopáusicas ( $>1$ año de amenorrea), de 55,9 \pm 8,1 años de edad (mediana: 54 años), que tenían útero y no habían empleado ninguna terapia de sustitución hormonal. Después de un ayuno nocturno, se tomo una muestra de sangre para 
medir la glucemia y el perfil lipídico. Además, se recabaron los datos demográficos, se midió la circunferencia en la cintura y la presión arterial y se aplicó el cuestionario específico para medir la calidad de vida durante la menopausia denominado MENQOL.

Los síntomas encontrados con mayor frecuencia fueron las oleadas de calor $(53,3 \%)$, la sudoración $(49,2 \%)$, la pérdida de memoria $(80,6 \%)$, la depresión $(67,4 \%)$, lo dolores musculares y articulares $(84,0 \%)$, la resequedad de la piel $(85,5 \%)$, la evasión a la intimidad $(76,2 \%)$ y los cambios en el deseo sexual $(76,5 \%)$. La población estudiada presentó algunas similitudes y diferencias, en comparación con las mujeres menopáusicas de otros grupos étnicos. Esas diferencias deben estudiarse con mayor profundidad, aunque las características socioeconómicas y demográficas pueden explicar algunas de ellas. Por ejemplo, la paridad, los síntomas vasomotores y los trastornos sexuales no estuvieron relacionados con una mayor tasa de síntomas menopáusicos en este estudio, como se ha observado en otros estudios realizados en mujeres ecuatorianas de bajos ingresos.

Durante la transición menopáusica aparecen algunas manifestaciones relacionadas con el síndrome metabólico — como la hipertensión, la hiperinsulinemia, el perfil lipídico aterogénico y la diabetes-, que a su vez aumentan el riesgo cardiovascular. En la población estudiada se encontró una mayor prevalencia de síndrome metabólico $(41,5 \%)$, hipertensión arterial $(38,8 \%)$, hiperglucemia $(16,6 \%)$, hipertrigliceremia $(56,9 \%)$ y obesidad abdominal $(54,2 \%)$, en comparación con otras poblaciones. La característica diagnóstica más importante encontrada en las mujeres con síndrome metabólico, según el criterio adoptado por el Tercer Panel de Tratamiento de Adultos (ATP III), fue la obesidad abdominal $(83,7 \%)$. Los niveles elevados de triglicéridos y la obesidad abdominal elevaron el riesgo de sufrir oleadas de calor, mientras que la mayor edad y el tener 5 años o más de menopausia lo redujeron. La hipertrigliceremia también incrementó el riesgo de sufrir sudoraciones.

Estos resultados confirmaron que la tasa de depresión en las mujeres postmenopáusicas que presentaban obesidad abdominal es mayor que en las no obesas, además de presentar dolores musculares $\mathrm{y}$ articulares en mayor grado. Las mujeres con niveles elevado de glucemia en ayunas ( $>110 \mathrm{mg} / \mathrm{dL}$ ) presentaron un mayor riesgo de resequedad de la piel y de cambios en su deseo sexual. La mayor edad también se asoció significativamente con una mayor frecuencia de resequedad de la piel.

En conclusión, la frecuencia de síntomas menopáusicos en esta población de mujeres ecuatorianas fue similar a la encontrada en otras poblaciones de mujeres latinoamericanas y de otras regiones y estuvo asociada con la edad y el estado hormonal y metabólico. Se observó una asociación significativa entre la obesidad abdominal y la presencia de síntomas menopáusicos. Se deben recomendar cambios en el estilo de vida y en los hábitos alimentarios, ya que constituyen medidas eficaces y sencillas para mejorar la calidad de vida y reducir el riesgo cardiovascular en las mujeres postmenopáusicas. (Chedraui P, Hidalgo L, Chávez D, Morocho N, Alvarado $\mathrm{M}$, Huc A. Menopausal symptoms and associated risk factors among postmenopausal women screened for the metabolic syndrome. Arch Gynecol Obstet. 2007;275:161-8.)

\section{Adaptación al español de una escala de evaluación del miedo a la muerte}

Los cuestionarios para medir la ansiedad ante la muerte deben medir las diversas dimensiones de la actitud ante la muerte. La ansiedad es un concepto multidimensional que puede tener diversas causas, lo que lleva a las personas a reaccionar de forma diferente ante la idea de la muerte como un estado y de la muerte como proceso. De igual manera, la actitud y las reacciones emocionales pueden diferir cuando se trata de la muerte propia o de la ajena. La escala de miedo a la muerte de ColletLester (EMMCL) es uno de los instrumentos multidimensionales clásicos empleados para evaluar la actitud ante la muerte y es el único que permite distinguir entre la muerte y el proceso de morir, tanto con respecto a la muerte propia como a la ajena. Para ello, esta escala está estructurada en cuatro subescalas específicas independientes.

En este trabajo se expone el proceso de adaptación de la EMMCL al español, se determinan sus propiedades psicométricas (consistencia interna, confiabilidad y estructura factorial) y se establece la correlación de esa escala con otras que miden la ansiedad ante la muerte y la ansiedad en general.

Inicialmente, dos expertos bilingües tradujeron por separado las 28 preguntas de la EMMCL del inglés al español. Después, dos sicólogos revisaron la traducción y se sucedieron ciclos de correcciones y revisiones hasta lograr una versión definitiva de consenso. Luego se tradujo esa versión definitiva del español al inglés y se comparó con la versión original en inglés. Ambas versiones mostraron una gran similitud.

Para su validación, la versión final en español se aplicó a 109 enfermeras graduadas (tasa de respuesta: 76,43\%) y 172 estudiantes de enfermería (tasa de respuesta: 96,22\%), todos españoles; de ellos 64 hombres y 217 mujeres. La edad media de las enfermeras fue de 36,4 años (desviación están- 